\title{
Hugo Alvaro Ruiz
}

Hugo Ruiz fue un amigo siempre dispuesto a servir con generosidad, calor humano y lealtad y un profesional ejemplar de la salud. Médico educado en aulas de España, especializado en salud pública en la Universidad Nacional de Colombia y en salud materno-infantil en la Universidad de Antioquia, se entregó de lleno a servir al país. En su larga trayectoria profesional ocupó los siguientes cargos directivos: Director del Centro de Salud de Agua de Dios, Director del Distrito Integrado de Salud de Girardot, Coordinador del Programa de Extensión Rural de Servicios de Protección Materno-Infantil y Jefe de la Oficina de Planeación, en la Secretaría Departamental de Salud de Cundinamarca; Jefe de Enfermedades Crónicas, Jefe de la División de Epidemiología, Jefe de la División de Atención Médica y Subsecretario de Salud de Bogotá.

Como investigador científico del Instituto Nacional de Salud, desde 1978 recorrió el país, desde Nariño hasta la Costa Atlántica, desde Guaviare hasta la zona del Pacífico, realizando estudios de gran importancia para un mejor conocimiento del estado de salud de la población y enfrentando con profesionalismo incansable los obstáculos que pudieran presentarse.

Participó en la realización de tres grandes encuestas nacionales de salud pública: el Estudio Nacional de Salud, 1977-1980; la de Conocimientos, Actitudes y Prácticas de Salud, 19861989, y la de Prevalencia de los Desórdenes por Deficiencia de Yodo e Ingestión Promedio de Sal, 1994-1998, obras gigantescas por la cantidad de hogares visitados y los riesgos enfrentados ante la situación de orden público de muchas regiones.

Hoy disponemos de información confiable sobre esos aspectos merced al ahínco, la honestidad y el entusiasmo con que Hugo Ruiz dirigió las operaciones de campo que, en el caso de la última encuesta, sirvió de base para obtener en 1998, la declaratoria de Colombia como país libre de desórdenes por deficiencia de yodo, otorgada por la OPS/OMS y la UNICEF.

El análisis de los datos recolectados le permitió dejar valiosos trabajos en los que se describen con objetividad las condiciones de salud de amplios sectores de la población. Entre sus publicaciones merecen mención los manuales de operativa, del médico examinador, de entrevistas domiciliarias, del supervisor y del personal auxiliar y el documento de seguridad social del Estudio Nacional de Salud; el área de investigación del Programa de Consolidación del Sistema Nacional de Salud; los manuales de operativa, entrevistas domiciliarias y toma de medidas antropométricas y los documentos de seguridad social, características de la población, y el volumen de salud maternoinfantil, sustancias psicoactivas y tercera edad, de la Encuesta sobre Conocimientos, Actitudes y Prácticas en Salud, y, por último, el de prevalencia de bocio en los indígenas de la Sierra Nevada de Santa Marta (kogi-arhuacos) y de prevalencia de los desórdenes por deficiencia de yodo e ingestión promedio de sal.

Despedimos así al amigo y al colega. Lo extrañaremos.

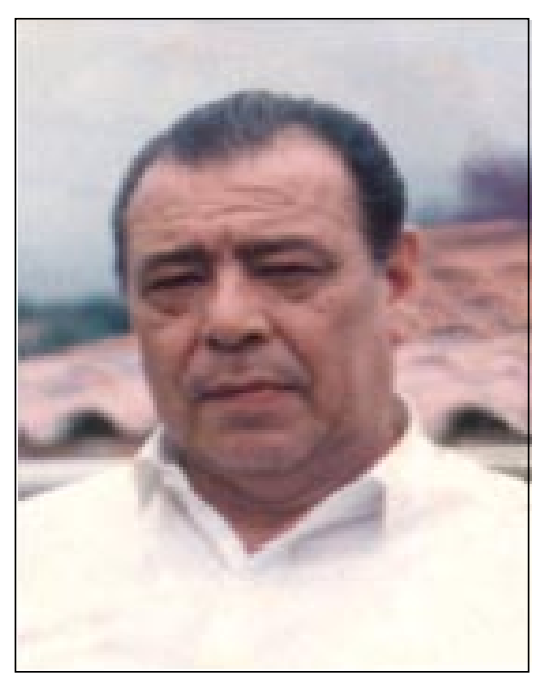

